\title{
¿Ruptura o reforma? La hermenéutica del Concilio Vaticano II en los escritos de Joseph Ratzinger
}

\author{
Pablo Blanco Sarto \\ FACULTAD DE TEOLOGÍA \\ UNIVERSIDAD DE NAVARRA
}

«Apenas concluido el concilio -sostenía el teólogo O. H. Pesch-, se afirmó durante casi media década una interpretación eufórica del mismo, que en sustancia consideraba los textos conciliares como ya superados en el acto de su promulgación y comprendía el concilio simplemente como un factor que habría puesto a la Iglesia en movimiento hacia un nuevo inicio radical en el futuro [...]. Una actitud semejante no está justificada ni por la letra ni por el así llamado "espíritu" de los textos conciliares. Por este motivo, la primera regla [hermenéutica] suena así: Ningún concilio puede ser interpretado por principio contra la tradición de la Iglesia» ${ }^{1}$. Desde el momento de su clausura hasta la actualidad, las valoraciones sobre el significado del concilio Vaticano II han girado en torno a su continuidad o discontinuidad con la tradición dogmática y el magisterio precedente ${ }^{2}$.

1 O.H. Реsch, Das Zweite Vatikanische Konzil. Vorgeschichte, Verlauf - Ergebnisse, Nachgeschichte (Würzburg 1993) 149.

2 La producción reciente sobre el concilio Vaticano II es enorme: vid. W. Kasper, Teologia e Iglesia (Barcelona 1989) 401-415; M. FAGgioli, "Concilio Vaticano II: bollettino bibliografico (2000-2002)», en Cristianesimo nella Storia 24 (2003) 335360; "Concilio Vaticano II: bollettino bibliografico (2002-2005)", Cristianesimo nella Storia, 26 (2005) 743-767; "Council Vatican II: Bibliographical Overview 2005-2007», Cristianesimo nella Storia , 29 (2008) 567-610; "Council Vatican II: Bibliographical overview 2007-2010», Cristianesimo nella Storia, 32 (2011) 755791; G. Routhier, "Un concile à interpreter. Les enjeux d'un style nouveau», Études 4065 (2007/2) 627-637; Vatican II. Herméneutique et réception (Québec 2006); ID. ET ALII, «Recherches et publications récentes autour de Vatican II», Laval théologique et philosophique 53 (1997) 435-454; Laval théologique et philosophique 55 (1999) 115-149; Laval théologique et philosophique 56 (2000) 543-583; Laval théologique et philosophique 58 (2002) 605-611; Laval théologique et philosophique 60 (2004) 561-577; Laval théologique et philosophique 61 (2005) 613-653; Laval théologique 
En estas páginas tan solo pretendemos realizar una lectura de los textos del teólogo Ratzinger sobre el post-concilio y su hermenéutica, a partir de las cuatro constituciones conciliares. Las fechas nos permiten además hacer una aportación. Existe la conocida tesis del große Wende, del «gran giro» que llevaría de un primer a un segundo Ratzinger ${ }^{3}$. Por un lado, la misma cronología ofrece datos evidentes de que estas ideas ya las defendía el teólogo alemán al menos desde la época conciliar ${ }^{4}$; aquí veremos además que estas posturas se pueden encontrar de igual manera antes del emblemático 1968 y de la estancia del profesor Ratzinger en Tubinga. Así, autores más recientes insisten en que «la visión teológica de Ratzinger [...]

et philosophique 64 (2008) 783-824; Laval théologique et philosophique 67 (2011) 321-373. Para las diversas valoraciones acerca de la continuidad o discontinuidad, vid. G. Wassillowsky, «Das II. Vatikanum - Kontinuität oder Diskontinuität?: zu einigen Werken der neuesten Konzilsliteratur», Communio 34 (2005) 630-640; F.X. BIschof, «Steinbruch Konzil? Zu Kontinuität und Diskontinuität kirchlicher Lehrentscheidungen", Münchener Theologische Zeitschrift 59 (2008) 194-210; B. Gherardini, Concilio Ecumenico Vaticano II. Un discorso da fare (Frigento 2009); M.L. Lamb - M. Levering, «Introduction», ID. (eds.), Vatican II (New York 2008); G. NARCISSE, "Interpréter la tradition selon Vatican II: rupture ou continuité?», Revue thomiste 110 (2010) 373-382; N. Ormerod, "Vatican II - continuity or discontinuity?: toward an ontology of meaning», Theological studies 71 (2010) 609636; G. MuccI, "Continuità e discontinuità del Vaticano II", La Civiltà cattolica 161 (2010) n. 3834, 579-584; G. Richi, "A propósito de la "hermenéutica de la continuidad" ", Scripta theologica 42 (2010) 59-77; S. Pie Ninot, "Ecclesia semper reformanda. La recepción del Vaticano II: balance y perspectivas», Revista catalana de teología 37 (2012) 281-302.

3 R. Tura, "Joseph Ratzinger», P. Vanzan - H.J. Schulz (eds.), Lessico dei teologi del secolo XX (Brescia 1978) 750-752. Esta postura viene expuesta de modo amplio -en la línea de Hans Küng- por Hermann HärING en Theologie und Ideologie bei Joseph Ratzinger (Patmos, Düsseldorf 2001), donde se propone el supuesto Wende como clave interpretativa de todo su pensamiento (cf. 22-40), a lo que se une la continua acusación a Ratzinger de "platonismo" y de Meinungsdiktatur (cf. 195-198). Le reprocha a su vez un enfoque ideológico y «teopolíco» con argumentos históricos, sociológicos e ideológicos de claro cuño centroeuropeo, al mismo tiempo que clama por una alianza con el pensamiento posmoderno (cf. 195-198). Llama sin embargo la atención las poco frecuentes referencias a los textos ratzingerianos. En esta línea se sitúa también O. Putz, “"I Did Not Change; They Did!” Joseph Ratzinger, Karl Rahner and the Second Vatican Council», New Witneskins 2 (2007/1) 11-31.

4 Esto lo he visto en «El concilio de Joseph Ratzinger. Notas sobre su actividad durante el Vaticano II", Anuario de Historia de la Iglesia 21 (2012) 245-281; reproducido en Aa.Vv., Creo en la Iglesia. Reflexiones en torno al 50 aniversario del concilio Vaticano II, CDSCO, Lima 2012, 78-113. 
ha mostrado una clara continuidad durante más de cincuenta años» ${ }^{5}$. En su visión teológica, más que entrar en una dialéctica entre progresistas y conservadores, el teólogo alemán quería más bien ir a lo esencial, back to fundations, como dice Nichols ${ }^{6}$. Reforma, no ruptura: es esta la tesis que queremos probar en estas líneas y que, en nuestra opinión, constituye una constante en el pensamiento ratzingeriano ${ }^{7}$.

\section{Conceptos previos}

La hermenéutica conciliar ha sido una de los temas teológicos de los últimos tiempos ${ }^{8}$. En primer lugar, partiremos de una serie de pre-

5 L. Boeve, «Introduction. Joseph Ratzinger: his life, work and thought», G. Mannion, "Preface. Mapping a theological journey», L. Boeve - G. Mannion, The Ratzinger Reader (New York 2010) 12; L. Boeve, "La vrai réception de Vatican II n'a pas encore commencé". Joseph Ratzinger, Révélation et autorité de Vatian II» en G. Routhier - G. Jobin (dir.), L'autorité et les Autorités. L'hermeneutique théologique de Vatican II, Unam Sanctam (Nouvelle Série 3, Paris 2000) 13-50; puede verse también en esta misma línea: W. Kraning, «Einleitung», W. Kraning (Hg), Ich glaube (Leipzig 1979) 13, donde habla más bien de una messianische Theologie siempre coherente con sus principios; F. Schüsler FiorenZA, «From theologian to pope: A personal view Back, past the public portrayals», Harvard divinity bulletin 33 (2005/2) 56-62; J.A. Komonchaк, "The Church in crisis: Pope's Benedict theological vision», Commonweal (3.6.2005) 11-14; C. Gutiérrez, "Presupuestos de la teología de J. Ratzinger», Ecclesia (2007/2) 215-216; T. Rowland, La fe de Ratzinger. La teología del papa Benedicto XVI (Granada 2008) passim; U. CASALE, "Introduzione» a Fede, ragione, verità e amore. La teologia di Joseph Ratzinger. Un'antologia (Torino 2009) 51, n. 112.

6 Cf. A. Nichols, The theology of Joseph Ratzinger: an introductory study (Edimburgh 1988) 225-240. Es la tesis mantenida también en el título del homenaje presentado por el Schülerkreis con motivo de su setenta cumpleaños en AA.VV., Vom Wiederauffinden der Mitte. Grundorientierungen. Texte aus vier Jahrzehnten (Freiburg 1997).

7 Sobre el concilio como ruptura, tenemos por ejemplo el artículo de Karl Rahner titulado "Theologische Grundinterpretationen des II. Vatikanischen Konzils», Schriften zur Theologie XIV (Zürich 1980) 287-302. Esta perspectiva del concilio como «nuevo comienzo» está magníficamente expuesta en S. Madrigal, Karl Rahner y Joseph Ratzinger. Tras las huellas del concilio (Santander 2006) 19-97. Puede verse también O. Putz, “"I Did Not Change; They Did!” Joseph Ratzinger, Karl Rahner and the Second Vatican Council», 11-31. Sobre la "hermenéutica de la reforma» puede verse J.W. O'MALLEY, “The hermeneutic of reform”: a historical analysis», Theological studies 73 (2012) 517-546.

8 Puede verse, por ejemplo, V. Botella, El Vaticano II en el reto del tercer milenio: hermenéutica y teología (Salamanca 1999); P. Hünermann, "Kriterien für die 
misas terminológicas, tal como las entiende el mismo Ratzinger ${ }^{9}$. En una temprana intervención de $1965^{10}$, el joven perito conciliar acudía al comentadísimo concepto de aggiornamento. Se refería allí al «entusiasmo» inicial que despertó esta palabra, así como la consecuente «superación de un anacronismo». En efecto, el concilio quiso «tomar en consideración los problemas específicos del hombre moderno, y llevar a

Rezeption des II. Vatikanischen Konzils», Theologische Quartalschrift 191 (2011) 126-147; ID., «El 'texto' pasado por alto sobre la hermenéutica del concilio Vaticano II», Concilium 312 (2005) 139-162; H. WitTe, "Reform with the help of juxtapositions: a challenge to the interpretation of the documents of Vatican II", The Jurist 71 (2011) 20-34; J. RAHnER, "Öffnung nach außen - Reform nach innen: zur ökumenischen Hermeneutik des Konzils», Una Sancta 65 (2010) 137-154; G. Ruggeri, «Para una hermenéutica del Vaticano II», Concilium 279 (1999) 13-28; A.M. BARRATT, "Interpreting Vatican II forty years on: a case of "caveat lector"", The Heythrop journal 47 (2006) 75-96; G. Routhier, Vatican II: herméneutique et réception (Montréal, 2006); L. Villemin, "L'herméneutique de Vatican II. Enjeux d'avenir» en PH. Bordeyne -L. Villemin (dir.), Vatican II et la théologie. Perspectives pour le XXIè siècle (Paris, 2006) 247-262; G. JobIn -G. Routhier (dir.), L'autorité et les autorités. L'herméneutique théologique de Vatican II (Paris, 2010); O. Rush, Still Interpreting Vatican II: Some Hermeneutical Principles (New York-Mahwah, 2004); K. LehmanN, «Hermeneutik für einen künftigen Umgang mit dem Konzil» en G. Wassilowsky (Hg.), Zweites Vatikanum: vergessene Anstösse, gegenwärtige Fortschreibungen (Freiburg im Br., 2004) 71-89.

9 Como bibliografía crítica, puede verse: D. Коsch, «Schriftauslegung als Seele der Theologie. Exegese im Geist des Konzils», en Freiburger Zeitschrift für Philosophie und theologie 38 (1991) 205-233; S. LEFEBVRE, «El conflicto de las interpretaciones del concilio: el debate entre Ratzinger y Kasper», en Concilium 314 (2006) 111-122; S. Madrigal, Karl Rahner y Joseph Ratzinger, 99-I82; J. KомоNCHAK, «Benedict XVI and Vatican II», en Cristianesimo nella storia 28 (2007) 335; O. Putz, "I Did Not Change; They Did!” Joseph Ratzinger, Karl Rahner and the Second Vatican Council», 11-31; M. Heım, "Konziliare Setreiflichter auf die Theologie Joseph Ratzingers / Benedikts XVI. Vortrag in Natz-Schabs (Südtirol) am 22. Oktober 2011», en Mitteilungen Institut Papst Benedikt XVI. 4 (2011) 50-58; R. Weimann, «Hermeneutik der Reform als Erneuerung in Kontinuität», en Mitteilungen Institut Papst Benedikt XVI. 4 (2011) 50-58, 59-82.

10 «Angesichts der Welt von heute. Überlegungen zur Konfrontation mit der Kirche im Schema XIII», en Wort und Wahrheit 20 (1965) 493-504; versión ampliada: «Der Christ und die Welt von heute. Überlegungen zum sogenannten Schema XIII des Zweiten Vatikanischen Konzils», B. Metz (Hg.), Weltverständnis im Glauben, Maguncia 1965, 143-160; versión revisada: «Der Christ und die Welt von heute», Dogma und Verkündigung (München 1973) 183-204; tr. esp.: Palabra en la Iglesia (Salamanca 1976) 147-164. 
ellos la esperanza cristiana en su situación concreta» ${ }^{11}$. Así, el concepto "mundo" ocupó el centro de las reflexiones conciliares: "si al principio constituía una actitud moral, pronto adquirió un carácter ontológico». Así, la secularización respondería a una orientación esencial de la fe. «El cristiano debería aspirar a un mundo secularizado, y no sacralizado, numinosos o divinizado", se repetía. Esto comportaría también la disolución de la obra creadora y salvadora en el tiempo y en la historia. «En esta tarea -criticaba Ratzinger- el optimismo de la teología de la secularización tropezó con la sagrada Escritura, que dice cosas muy diferentes respecto al mundo» ${ }^{12}$. Según Routhier, Ratzinger ve el concilio en continuidad crítica con las aportaciones de la Escritura, los Padres, los concilios y el magisterio anteriores, y de este modo «tocaba el punto más sensible» ${ }^{13}$. Es decir, nos estamos enfrentando con una verdadera actitud metodológica.

\section{Aggiornamento}

«La gozosa emoción que provocó la idea de aggiornamento hace tiempo que se ha apagado", diagnosticaba ya Ratzinger en una conferencia sobre la renovación en la Iglesia pronunciada en Münster en ese mismo año de $1965^{14}$. La situación eclesial se había polarizado al pasar de una aceptación acrítica que los imperativos de la modernidad al rechazo de todo el concilio o de parte de él. «Y ahí están, entre dos piedras de molino, los que han luchado y sufrido por la renovación de la Iglesia, y que ahora se preguntan si las cosas no iban mejor en tiempos de los conservadores, que bajo el dominio del "progresismo" ${ }^{15}$. Tras esta captación de la atención del público allí presente procedía a estudiar el «sentido fundamental de la renovación cristiana». La renovación no procura destruir la Iglesia, sino «sacarla a la luz con su primitiva fuerza y pureza». Lo que se

\footnotetext{
11 Palabra en la Iglesia 148.

12 Palabra en la Iglesia 149.

13 G. Routhier, «Un concile à interpreter. Les enjeux d'un style nouveau», 629. Sobre esta cuestión, puede verse: M.L. LAMB - M. Levering, «Introduction», 4-5.

14 "Was heißt Erneuerung der Kirche?», Diakonia 1 (1966) 303-316; después en Das neue Volk Gottes. Entwürfe zur Ekklesiologie, Patmos, Düsseldorf 1969, $267-$ 281; Kirche - Zeichen unter den Völkern. Schriften zu Ekklesiologie und Ökumene, Gesammelte Schriften 8/2 (=JRGS 8/2) (Freiburg-Basel-Wien 2010) 1186-1201.

15 J. Ratzinger, Gesammelte Schriften 8/2, 1186-1187.
} 
busca es el «sí a lo cristiano», la «revitalización del cristianismo» ${ }^{16}$. Así, la pregunta será "¿qué es lo cristiano?», y no tanto "¿qué exigen los tiempos modernos?». ¿Encontraremos así el verdadero sentido de la renovación?, se preguntaba para establecer unos presupuestos hermenéuticos, a partir de los cuales leer el Concilio.

Como hizo antes Congar ${ }^{17}$, Ratzinger se preguntaba por la verdadera y la falsa renovación en la Iglesia, para evitar «falsos ensayos de reforma a derecha e izquierda». Jesús no siguió ni la renovación de fariseos y esenios ni la de los saduceos. "Lo que importa no es que se hagan muchas cosas, sino que brille la verdad en la veracidad (Wahrhaftigkeit), porque la verdad sin la veracidad ha perdido su alma, y queda sin eficacia incluso siendo verdad $\aleph^{18}$. Realiza entonces nuestro autor un erudito recorrido por las antigüedades judaicas, cuyo paralelismo con el presente no es difícil de establecer. «Israel es un espejo del mundo y la problemática de Israel es la problemática del mundo de hoy» ${ }^{19}$. Por eso se ha de evitar tanto un antirreformismo zelotista, como un progresismo saduceo que solo busca el cambio por el cambio. "Hay un tipo de teología antiteológica, en la que la hermenéutica degenera en tergiversar la totalidad del mensaje cristiano en palabras sin contenido, y demostrar que significan poco más o menos lo contrario de lo que normalmente sería su sentido $»^{20}$. Según Ratzinger, esta postura no atrae a nadie al cristianismo. Para él, «no es necesario estar metido en los datos y en los requisitos de este mundo; el cristiano debe familiarizarse con las cosas de Dios» ${ }^{21}$. Con lo que concluye con la siguiente definición: «Renovación es simplificación, no en el sentido de recortar o empequeñecer, sino en el sentido de hacerse sencillo, de volver a la verdadera sencillez, que es el misterio de la vida $»^{22}$.

Siguió indagando en uno de los temas que han ocupado su producción teológica: el concilio y su aplicación en el posconcilio. A un año del

\footnotetext{
16 Cf. J. Ratzinger, Gesammelte Schriften 8/2, 1189-1190.

17 Vraie et fausse réforme dans l'Église (Paris 1950); cf. J.W. O'Malley, "The hermeneutic of reform": a historical analysis», 520ss.

18 J. Ratzinger, Gesammelte Schriften 8/2, 1197.

19 J. Ratzinger, Gesammelte Schriften 8/2, 1199.

20 J. Ratzinger, Gesammelte Schriften 8/2, 1201.

21 J. Ratzinger, Gesammelte Schriften 8/2, 1201-1202.

22 J. Ratzinger, Gesammelte Schriften 8/2, 1202.
} 
término del evento conciliar, en una intervención en el Katholikentag de $1966^{23}$, Ratzinger volvía a plantear la pregunta: ¿Cómo ha sido entendida hasta el momento en Alemania la fusión entre la Iglesia y el mundo?, ¿hasta qué punto ha sido asimilado el concilio «crítica y positivamente»? Tras un entusiasmo inicial, había llegado una situación en que la fe resulta más «más trabajosa y expuesta, y menos protegida» ${ }^{24}$, volvía a constatar. Para unos el concilio era demasiado; para otros, demasiado poco. «Lo cierto -concluye- es que ahora los fieles están menos unidos que antes $\aleph^{25}$. Aludiendo a la reforma iniciada por Teresa de Ávila, añadía a su vez de un modo crítico y tal vez algo provocador: la santa «tiró por la ventana el aggiornamento y creó la renovación que no era concesión, sino exigencia urgente de entregarse a la expropiación escatológica de Cristo ${ }^{26}$. La táctica de la fundadora era más bien la de la reforma y la renovación. Es más, añadía, ¿̨no había tomado aquel primerísimo posconcilio precisamente el camino contrario, confundiendo el aggiornamento con la mera modernización estructural, sin ir a las raíces de la verdadera reforma?

Este diagnóstico se repetirá a lo largo de los años. En otra intervención oral publicada ya en 1968, Ratzinger mantenía más o menos las mismas ideas y se refería a que la «mayoría conciliar» no habría deseado crear una ruptura con la tradición ni mucho menos construir una nueva Iglesia. Bajo la insignia de aggiornamento, el posconcilio se habría embarcado en una reforma «sin criterio», es decir, sin un objetivo claro ${ }^{27}$. El concilio había hecho en realidad otro tipo de propuestas. La originalidad del Vaticano II -añadía más adelante- consiste en que, a partir

23 «Der Katholizismus nach dem Konzil - Katholische Sicht», Auf Dein Wort hin. 81. Deutscher Katholikentag (Paderborn 1966) 245-266; Klerusblatt 46 (1966) 279285; versión ampliada "Der Katholizismus nach dem Konzil», Das neue Volk Gottes, 302-321; tr. fr.: Documentation Catholique 63 (1966) 1557-1556; tr. it.: Studi cattolici 69 (1966) 44-47; tr. ingl.: The Furrow 18 (1967) 3-23; tr. esp.: Palabra 17 (1967) 8-10; después en El nuevo pueblo de Dios. Esquemas para una eclesiología (Barcelona 1972) 335-356.

Cf. El nuevo pueblo de Dios. Esquemas para una eclesiología 336. El nuevo pueblo de Dios. Esquemas para una eclesiología.

El nuevo pueblo de Dios. Esquemas para una eclesiología 337. Sobre este tema, puede verse S. MADrigal, Karl Rahner y Joseph Ratzinger, 137-141.

27 Cf. H. Jedin, Vatikanum II und Tridentinum. Tradition und Fortschritt in der Kirchengeschichte (Köln-Oppladen 1968) 31. 
de ese momento, se conjugaban las instancias histórica y doctrinal. Así, por ejemplo, en la cuestión hermenéutica, además de la interpretación magisterial, se daban los análisis realizados por la razón y la historia ${ }^{28}$. Sin embargo, este reconocimiento del desarrollo histórico del dogma no significaría entronizar al Vaticano II como una época nueva, que nada tenía que ver con las anteriores. La situación de entonces requería una fidelidad de la que «adquiriría de nuevo valor el esencial hecho doctrinal ${ }^{29}$. Para el teólogo Ratzinger, aggiornamento sería permanecer en lo esencial de la fe, a través del abandono de los aspectos accidenta$\operatorname{les}^{30}$. El aggiornamento tendría bastante que ver con el ressourcement, con la vuelta a las fuentes ${ }^{31}$.

De esta forma, concluía, el Vaticano II puede ser calificado como «relectura» de una situación precedente conforme a unos nuevos criterios, mientras era confirmado lo esencial. En esta dinámica de la relectura, sería posible encontrar una dinámica de la continuidad por medio del desarrollo doctrinal ${ }^{32}$. En este sentido, añadirá más adelante, no basta con criterios sociológicos, políticos o jurídicos, sino que se requiere una perspectiva doctrinal o teológica, en la que la Escritura, la tradición y

28 Cf. Vatikanum II und Tridentinum. Tradition und Fortschritt in der Kirchengeschichte 44-45.

29 Vatikanum II und Tridentinum. Tradition und Fortschritt in der Kirchengeschichte 46.

30 Cf. Vatikanum II und Tridentinum. Tradition und Fortschritt in der Kirchengeschichte 46-47; remite allí a la biografía de F.M. Willam, Von jungen Angelo Roncalli (19031907) zum Papst Johannes XXIII. (1958-1963). Eine Darlegung vom Werden des Aggiornamento-Begriffes 1903-1907 als Leitidee für das II. Vatikanische Konzil und die Durchführung seiner Beschlüsse (Innsbruck 1967). Puede verse la recensión en Theologische Quartalschrift 148 (1968/2) 236-241. Allí escribe: «Die Idee Aggiornamento ist zunächst nicht auf die Fragen der theologischen Doktrin oder auf die Veränderung und Erneuerung der Kirche bezogen, sondern hat ihre Wurzel im Ringen um die wahre Form der Heiligkeit» (238). Hemos de recordar también que Willam era un buen conocedor de Newman y de su doctrina sobre el desarrollo de la doctrina cristiana. Sobre el particular, puede verse R. Weimann, «Hermeneutik der Reform als Erneuerung in Kontinuität», 64-72, especialmente el apartado «Mandat zur Veränderung» en «Hermeneutik der Reform als Erneuerung in Kontinuität» 70-72.

31 Cf. J.W. O’MALley, “"The hermeneutic of reform”: a historical analysis», 536-542.

32 Cf. H. Jedin, Vatikanum II und Tridentinum, 47. 
el magisterio ofrecieran garantías de autenticidad ${ }^{33}$. El concilio no es un nuevo principio más que en el sentido de que ofrece una renovación de la fe de siempre: la que Cristo ha entregado a su Iglesia. Este juego interpretativo presentaba sus dificultades, tal como han destacado algunos autores ${ }^{34}$. Witte ha destacado en este sentido -según la mente de Ratzinger- la importancia de leer el Vaticano II a partir sobre todo de la Lumen gentium, a la luz de la Sacrosanctum concilium, para destacar la prioridad de la liturgia y de Dios sobre la Iglesia, tal como iremos viendo más adelante ${ }^{35}$. Estas ideas seguirán apareciendo con insistencia a lo largo de los años.

\section{Reforma}

Como vemos, se ha dado un deslizamiento del término aggiornamento hacia otro más amplio como el de "reforma" ${ }^{36}$. En la entrevista realizada en verano de $1984^{37}$, el cardenal prefecto animaba a «descubrir de nuevo el concilio». A pesar de que casi todo el mundo en la Iglesia habla sobre él, sería paradójicamente al mismo tiempo un gran desconocido. Existen dos interpretaciones dialécticamente enfrentadas: por un lado, «la corriente llamada "progresista" lo considera completamente superado desde hace tiempo»; por otro, "la corriente "conservadora" " considera que «el concilio es responsable de la actual decadencia de la Iglesia Católica y se le acusa incluso de apostasía respecto al concilio de Trento y al Vaticano I $\aleph^{38}$. En este sentido, recordaba que el Vaticano II se apoya en la autoridad de Trento y del Vaticano I: «El Vaticano II se encuentra en rigurosa continuidad con los dos concilios anteriores y recoge literal-

33 Cf. Vatikanum II und Tridentinum 57-58.

34 Cf. F.X. Bischof, «Steinbruch Konzil? Zu Kontinuität und Diskontinuität kirchlicher Lehrentscheidungen», 209-210.

35 Cf. H. Witte, «Reform with the help of juxtapositions: a challenge to the interpretation of the documents of Vatican II», 22.

36 Sobre la historia del término, véase J.W. O’MALLEY, “"The hermeneutic of reform”: a historical analysis», 522-536.

37 Informe sobre la fe (Madrid 1986); el autor ya se había pronunciado en «Balance de la época posconciliar. Fracasos, tareas y esperanzas» en Teoría de los principios teológicos (Barcelona 1985) 439-453; y en "Der Weltdienst der Kiche. Auswirkungen von 'Gaudium et spes' im lezten Jahrzent”, Communio 4 (1975) 439-454. Un balance crítico se encuentra en S. MADrigal, Karl Rahner y Joseph Ratzinger, 160-163. 
mente su doctrina en puntos decisivos ${ }^{39}$. No se puede estar a favor de uno de ellos y en contra de los demás, o dividir la Iglesia -como si no tuviera nada que ver la una con la otra- en preconciliar y posconciliar. Constataba de nuevo el cardenal prefecto la crisis de la Iglesia en los términos anteriormente expuestos, "hasta el punto de que -en palabras de Pablo VI, se ha pasado de la autocrítica a la autodestrucción» ${ }^{40}$.

Por eso la proclama del cardenal era: «descubramos el verdadero Vaticano II». Era una premisa, un presupuesto terminológico y metodológico. "Estoy convencido de que los males que hemos experimentado en estos veinte años no se deben al concilio "verdadero", sino al hecho de haberse desatado en el interior de la Iglesia ocultas fuerzas agresivas, centrífugas, irresponsables o simplemente ingenuas, de un optimismo fácil, de un énfasis en la modernidad, que ha confundido el progreso técnico actual con un progreso auténtico e integral $»^{41}$. En el exterior estaría la consabida «revolución cultural». No se trata por tanto de mirar atrás, sino de "volver a los textos auténticos del auténtico Vaticano II». Las cuatro constituciones conciliares ofrecen un concierto a cuatro voces donde se expresa el espíritu del concilio. No debe hablarse pues de «ruptura» en las enseñanzas del concilio respecto al resto del magisterio de la Iglesia: «Muy al contrario, existe una continuidad que no permite ni retornos al pasado ni huidas hacia delante, ni nostalgias anacrónicas ni impaciencias injustificadas. Debemos permanecer fieles al hoy de la Iglesia; no al ayer o al mañana: y este hoy de la Iglesia son los documentos auténticos del Vaticano II $»^{42}$.

La reforma es necesaria en la Iglesia, compatible con la anteriormente menciona continuidad. «Es verdad que las reformas exigen tiempo, paciencia y que entrañan riesgos; pero no es lícito decir: "dejemos de hacerlas, porque son peligrosas". Creo que el verdadero tiempo del Vaticano II no ha llegado todavía». A lo que añade sin embargo un consejo y

\footnotetext{
39. Informe sobre la fe,

40 Y sentencia después Ratzinger: «Hay que afirmar sin ambages que una reforma real de la Iglesia presupone un decidido abandono de aquellos caminos equivocados que han conducido a consecuencias indiscutiblemente negativas» (Informe sobre la fe, 36); cf. también R. Weimann, «Hermeneutik der Reform als Erneuerung in Kontinuität», 61-64, 72-78.

41 «Hermeneutik der Reform als Erneuerung ...» 36-37.

42 «Hermeneutik der Reform als Erneuerung ...» 37.
} 
un augurio optimista: «La lectura de la letra de los documentos nos hará descubrir de nuevo su verdadero espiritu» ${ }^{43}$. No hay antagonismos ni oposición. Recuerda además que el concilio es una reforma desde el vértice que ha de llegar a todos los demás fieles. «Es decir-concreta-, todo concilio, para que resulte verdaderamente fructífero, debe ir seguido de una floración de santidad». Así ocurrió en Trento, y por eso tuvo lugar una "verdadera reforma»: «La salvación de la Iglesia viene de su interior; pero esto no quiere decir que no venga de arriba, es decir, de los decretos de la jerarquía ${ }^{44}$. La reforma viene a la vez de arriba y de abajo, de la cúpula y de la base, pero sobre todo desde dentro. En el fondo, todo viene de más arriba todavía: «Encuentro maravilloso que el Espíritu sea, una vez más, más poderoso que nuestras previsiones y juzgue de manera muy distinta a lo que imaginábamos. En este sentido, la renovación es callada, pero avanza con eficacia» ${ }^{45}$.

En esta entrevista con Messori, hablaba Ratzinger de nuevo sobre el sentido de la «verdadera reforma» según su modo de entenderla: «En sus estructuras humanas la Iglesia es semper reformanda. Con todo, es necesario entender de qué modo y hasta qué punto. El texto del Vaticano II que acabamos de citar [LG 43] nos ofrece ya una indicación muy precisa al hablar de la "fidelidad de la Esposa de Cristo", que no es puesta en entredicho por la infidelidad de sus miembros»" ${ }^{46}$. Destacaba así la necesidad de una conversión personal, que no puede esconderse en el anonimato. Los pecados no son de la Iglesia, Esposa de Cristo, sino nuestros, recordaba. Por eso, "debemos tener siempre presente que la Iglesia no es nuestra, sino suya. En consecuencia, las "reformas", las "renovaciones" -por apremiantes que sean-, no pueden reducirse a un celoso activismo para erigir nuevas y sofisticadas estructuras. [...] Verdadera "reforma", por consiguiente, no significa entregarnos desenfrenadamente a levantar nuevas fachadas, sino (al contrario de lo que piensan ciertas eclesiologías) procurar que desaparezca, en la medida de lo posible, lo que es nuestro, para que aparezca mejor lo que es suyo, lo que es de Cristo» ${ }^{47}$. Por eso los verdaderos reformadores han sido siempre los santos. «Lo

\footnotetext{
43 «Hermeneutik der Reform als Erneuerung ...» 46.

44 «Hermeneutik der Reform als Erneuerung ...»49.

45 «Hermeneutik der Reform als Erneuerung ...»51.

46 Informe sobre la fe, 58-59.

47 Informe sobre la fe, 61.
} 
que necesita la Iglesia para responder en todo tiempo a las necesidades del hombre es santidad, no managementr ${ }^{48}$. Como se sabe, esta entrevista despertó alguna polémica ${ }^{49}$.

48 Informe sobre la fe, 62.

49 Véase, por ejemplo, G. Thils, En dialogue avec 'Entretien sur la foi' (Louvain-laNeuve 1986); J. Rollet, Le Cardinal Ratzinger et la théologie contemporaine (Paris 1987); V. ZiÉLINsky, 'Afin que le monde croie': méditations d'un croyant orthodoxe à propos du livre du Cardinal Ratzinger "Entretiens sur la foi" (Paris 1989); J.G.H. Hoffmann, "L'Entretien sur la Foi' du Cardinal Ratzinger, matiére d'un dialogue oecuménique», La Pensée catholique 220 (1986) 28-37; H.U von Balthasar, recensión en Theologische Revue 82 (1986) 50-51; H. KüNG, "Kardinal Ratzinger, Papst Wojtyla und die Angst vor der Freiheit (1985). Nach langem Schweigen ein offenes Wort» en N. Greinacher - H. KüNG (Hg.), Katholische Kirche wohin? Wider den Verrat am Konzil (München-Zürich 1986) 389-407; F. Вiот, «Das Orthodoxieverständnis in Kardinal Ratzingers Buch 'Zur Lage des Glaubens'», Concilium 23 (1987) 345-350; S. Cipriani, "Il 'Rapporto sulla fede' del Cardinale Ratzinger", Asprenas. Rivista di science teologiche 32 (1985) 445-452; H. JoHen JASCHKE, «La Chiesa di fronte al 2000. Osservazioni sul rapporto Chiesa-mondo nel cardinal Joseph Ratzinger» en AA.VV., Alla scuola della verità: i settanta anni di Joseph Ratzinger (Cinisello Balsamo 1998) 146-168.

Surgen también críticas en el ámbito anglosajón e hispánico: J.K. ReID, «Article Review: The Ratzinger Report», Scottish Jounal of Theology 40 (1987) 125-133; E. Dufy, "Urbi, but non Orbi... the Cardinal, the Church, and the World», New Blackfriars 66 (1985) 272-278; E. Iglich - F. Kerr - J.O. Mills - R. Ombres, "The Cardinal, in summary», New Blackfriars 66 (1985) 262-270; F. KerR, "The Cardinal and Post-conciliar Britain", New Blackfriars 66 (1985) 299-308; N. Lash, "Catholic Theology and the Crisis of Clasicism», New Blackfriars 66 (1985) 279287; J.O. Mills - T. Radcliff, "Ratzinger on the Faith. A British Theological Response. To the Archbishops and Bishops of England and Wales», New Blackfriars 66 (1985) 259-261; J. M. Rist, «Ratzinger on the Faith: A Criticism of the Critics», New Blackfriars 66 (1985) 477-480; R. Velasco, Réplica a Ratzinger, a propósito de su libro "Informe sobre la fé" (Bilbao 1986); R. Franco, "Las ambigüedades de un libro claro, el Informe sobre la fe», Proyección 33 (1986) 15-26; M. TERrA, «Eco del informe Ratzinger. Fray Boff y el neogalicanismo brasileño", Nexo (Montevideo) 5 (1985) 33-45. Como destacaba de nuevo Pesch, «esta fórmula no se refiere al concilio mismo, sino tan solo a algunas interpretaciones del concilio. [...] Ratzinger se dirige solamente contra aquellos que, basándose en las múltiples formulaciones abiertas, ven el concilio solo como un factor que pone en movimiento y no como la codificación vinculante de una praxis vigente» (O. H. Pesch, Das Zweite Vatikanische Konzil, 159-160). 
También en una intervención sobre la reforma en 1990 en el meeting de Rimini ${ }^{50}$, el cardenal Ratzinger proponía como experiencia de punto de partida la constatación del desprestigio al que está sometida la Iglesia en ese momento y tal vez también en la actualidad. Ante tal situación, algunos querrían transformarla de acuerdo con sus sueños y aspiraciones, mientras otros se refugian en un pasado que tal vez nunca existió. Por eso caben en la Iglesia reformas útiles e inútiles. «Existe una fórmula que arroja luz para dar un primer paso. La Iglesia no es una democracia ${ }^{51}$, comienza diciendo. La Iglesia no surge de discusiones, acuerdos y consensos. No todo se ha de acomodar según el criterio de la mayoría. La voluntad de Cristo sobre su Iglesia resulta vinculante. «Una Iglesia cuyos fundamentos se apoyan en las decisiones de la mayoría, se transforma en una Iglesia puramente humana. [...] La opinión sustituye a la fe ${ }^{52}$. Para Ratzinger, la fórmula reformadora consiste en más santidad y menos burocracia, menos política, en el sentido peyorativo de la expresión. La «reforma verdadera» consistirá en liberarse de esas adherencias extrañas, demasiado humanas. "La reformatio, que es necesaria en todas las épocas, no consiste en el hecho de que podamos modelar una y otra vez "nuestra" Iglesia como más nos apetece, sino en el hecho de que siempre nos deshacemos de nuestras propias construcciones a favor de una luz purísima que viene de lo alto y que es, al mismo tiempo, irrupción de la pura libertad $»^{53}$.

\section{Palabra y liturgia}

Tras estas consideraciones terminológicas y metodológicas iniciales, pasemos a ver algunas manifestaciones más concretas de este plan renovador en la continuidad, siempre siguiendo las cuatro grandes constituciones conciliares. Empecemos pues por la Sacrosanctum concilium y la Dei verbum. Para Ratzinger todo ha de empezar por la Palabra y la liturgia, en las que se hace presente el mismo Cristo. No en vano, celebra que

50 «Una compagnia sempre riformanda», Communio 19 (1990) 91-105; tr. esp.: 30 días IV, 9, octubre 1990; Communio 13 (marzo-abril 1991) 154-172; después en Ser cristiano en la era neopagana, Encuentro, Madrid 1995, 13-28; recogido después en J. Ratzinger, Gesammelte Schriften 8/2, 1216-1230.

51 J. Ratzinger, Gesammelte Schriften 8/2, 1218.

52 J. Ratzinger, Gesammelte Schriften 8/2, 1219.

53 J. Ratzinger, Gesammelte Schriften 8/2, 1220. 
el primer texto aprobado por el concilio fue la constitución dogmática sobre la sagrada liturgia ${ }^{54}$. A un año del término del concilio, ya en una intervención en el congreso del Katholikentag de $1966^{55}$, Ratzinger se ocupaba de la «situación de la renovación litúrgica», por ser esta la manifestación más visible y evidente. En primer lugar, destacaba que la desaparición del latín en las celebraciones litúrgicas supondría perder ese vínculo de unidad con todos los demás católicos. «La segunda objeción -recapitulaba- se dirige hacia la comunidad, y evoca el silencio sagrado que se acomodaría al misterio mejor que el grito o las voces en alto" ${ }^{56}$. Además, a veces la celebración litúrgica caería en el activismo, en el puro movimiento. "Los actos externos ocuparían el lugar de lo verdaderamente auténtico: el encuentro y la unión con el Señor ${ }^{57}$. A esto habría que añadir una «dignidad estética» ausente en nuestras celebraciones. Para que se dé una verdadera renovación se requiere considerar la esencia de la liturgia, entendida como "confesión de fe y esperanza, súplica y acción de gracias, predicación y oración a la vez» ${ }^{58}$.

La reforma litúrgica

«En una liturgia así entendida -continuaba- la lengua no tiene la función de esconder, sino de revelar $"{ }^{59}$. El lenguaje tiene una cierta función fundamental en la celebración, en la que la dimensión revelativa ocupa un lugar preeminente. Porque lo central es la realidad que se hace presente. Así, en ciertas disposiciones parece que el sacerdote es el centro de la celebración, en vez del mismo Cristo, «con lo que se perfila en la

54 Cf. «Zum Eröffnungsband meiner Schriften» en Gesammelte Schriften. Theologie der Liturgie, Herder, Freiburg-Basel-Wien, 2008, 11 (J. Ratzinger, Gesammelte Schriften 11), 5-6.

55 «Der Katholizismus nach dem Konzil - Katholische Sicht», Auf Dein Wort hin. 81. Deutscher Katholikentag, 245-266; Klerusblatt 46 (1966) 279-285; versión ampliada «Der Katholizismus nach dem Konzil», Das neue Volk Gottes, 302-321; tr. fr.: Documentation Catholique 63 (1966) 1557-1556; tr. it.: Studi cattolici 69 (1966) 44-47; tr. ingl.: The Furrow 18 (1967) 3-23; tr. esp.: Palabra 17 (1967) 8-10; después en El nuevo pueblo de Dios, 335-356.

56 El nuevo pueblo de Dios 338.

57 El nuevo pueblo de Dios 339.

58 El nuevo pueblo de Dios 340.

59 El nuevo pueblo de Dios 
liturgia un cierto clericalismo ${ }^{60}$. Como consecuencia, la sencillez en la liturgia opta a veces por una simplificación no acorde con la realidad que contiene: "Y tampoco ha de olvidarse -añadía- que celebrar la cena del Señor significa por esencia celebrar una fiesta, y con la fiesta encaja la belleza festiva ${ }^{61}$. De manera que esta condición de partida debe llevar a la libertad y a la legítima variedad celebrativa. Por eso añade una recomendación para liturgistas y legisladores: «Todo esto significa que para la reforma litúrgica se requiere una gran capacidad de tolerancia dentro de la Iglesia; tolerancia que, en este terreno, es el escueto equivalente de la caridad cristiana. [...] Porque el culto divino más auténtico es la caridad $»^{62}$.

Ratzinger rechazaba así todo posible monismo litúrgico. Estas ideas aparecerán de nuevo años después de la promulgación de la constitución dogmática sobre la liturgia en la vida de la Iglesia. En una homilía dirigida a la conferencia episcopal alemana reunida en Fulda en 1982 y titulada "La vida litúrgica en las comunidades quince años después del concilio»" ${ }^{63}$, Ratzinger formulaba una pregunta comprometedora: "¿Cómo están hoy las cosas entre nosotros en cuanto a la vida litúrgica?». Esta pregunta crea sentimientos encontrados, recordaba. Tras hacer una breve contextualización de la teología de la comunidad desarrollada en el posconcilio, se refería también a la dimensión universal que tiene este sacramento, que no solo depende de las Iglesias locales y comunidades eclesiales (cf. Jn 11,52). «Por eso -concluye-, la liturgia cristiana, por más que viva siempre y solo aquí y ahora, en el lugar concreto y con su pretensión de dirigirse al sí de esta comunidad, es católica por su propia esencia, proviene de la totalidad, lleva a la totalidad, a la unidad con el papa, con los obispos, con los fieles de todos los lugares y tiempos» ${ }^{64}$. En este sentido, la liturgia sería auténtica en la medida que "“comunidades"

\footnotetext{
60 El nuevo pueblo de Dios 344.

${ }^{61}$ El nuevo pueblo de Dios 345.

62 El nuevo pueblo de Dios 346.

63 «Das gottesdinsliche Leben in den Gemeinden fünfzenhn Jahre nach dem Konzil» en J. Ratzinger, Gesammelte Schriften 11, 627-631. Sobre este tema, puede verse M. Heım, "Konziliare Setreiflichter auf die Theologie Joseph Ratzingers / Benedikts XVI. Vortrag in Natz-Schabs (Südtirol) am 22. Oktober 2011», 52-54.

64 J. Ratzinger, Gesammelte Schriften 11, 628.
} 
eclesiales precedentes dejan de tener un sacerdote propio y una liturgia propia» y se unan a la liturgia de toda la Iglesia.

En segundo lugar, seguía diciendo el recién nombrado arzobispo de Münich y Frisinga, el concilio nos ha recordado con énfasis que la liturgia, en el lenguaje de la Iglesia, significa actio. «La liturgia es una acción, y por eso existe la participatio actuosa, la participación activa de todos los fieles" ${ }^{65}$. Pero esto no significa que la liturgia deba ser hecha solo por la comunidad. "Generalizando un poco, esto ha llevado a que, al final, se comenzara a medir su éxito según su valor del entretenimiento». Sin embargo, repite de nuevo, lo importante no es lo que nosotros hacemos, sino lo que acontece en la liturgia: lo que Dios hace por medio de ella. No es una autocelebración de la comunidad, ni tampoco un simple banquete. "Eucaristía significa que la resurrección del Señor nos regala esa legitimación que nadie más puede darnos. Por esa razón, es demasiado poco designar la eucaristía como banquete de la comunidad. La eucaristía ha supuesto la muerte del Señor, y solo por este motivo puede ser don de resurrección " ${ }^{66}$. De esta forma se unen la dimensión convival con la sacrificial; la celebración eucarística sería a la vez e inseparablemente cena, sacrificio y «fiesta de la resurrección ${ }^{67}$.

Ciertas aplicaciones de la reforma le parecen a Ratzinger poco acordes con el mismo concilio. En la entrevista de 1985 no presentaba especiales novedades respecto a las opiniones formuladas con anterioridad. Por ejemplo, tras referirse a la traducción de la liturgia en lengua vernácula, que también acometió el concilio tridentino, afirmaba que «sería falso decir, con ciertos integristas, que la creación de nuevos cánones va en contra de la tradición de la Iglesia. Sin embargo, queda por ver hasta qué punto las distintas etapas de la reforma litúrgica después del Vaticano II han significado verdaderas mejoras o más bien trivializaciones» ${ }^{68}$. Insiste pues en la actualidad del uso del latín como lengua litúrgica, tal como aparece en SC 36, 54, 101, así como la diversidad de usos en la liturgia. La Iglesia ha evitado siempre el monismo litúrgico: "pluralismo, pero para todos», afirma. Además, no busca la liturgia la «eficacia espectacular», el «entretenimiento». "No proviene de lo que nosotros hacemos,

65 J. Ratzinger, Gesammelte Schriften 11, 629.

66 J. Ratzinger, Gesammelte Schriften 11, 629-630.

67 J. Ratzinger, Gesammelte Schriften 11, 630.

68 Informe sobre la fe, 132. 
sino del hecho de que aquí acontece Algo que todos nosotros juntos somos incapaces de hacer» ${ }^{69}$.

También abordaba en 1994 la música sacra que se había seguido en ocasiones de la reforma litúrgica ${ }^{70}$. Ratzinger calificaba de "confusa» la vida litúrgica del momento y de «desconcierto musical resultante de la introducción a medias de la reforma litúrgica». Constataba de nuevo la fractura eclesial: «Un abismo divide la historia de la Iglesia en dos mundos irreconciliables: el preconciliar y el posconciliar» ${ }^{71}$. Un teólogo amante de la música como él afirmaba que no existe un abismo entre la Iglesia anterior al concilio y el mismo Vaticano II: «Si ampliamos la mirada, podemos afirmar que la historia de la liturgia está siempre en tensión entre la continuidad y la renovación $»^{72}$. Por eso no nos sirven los antagonismos al uso entre progresistas y conservadores. «La pregunta es más bien: ¿qué es la liturgia en su misma esencia?, ¿qué norma establece ella misma? Solo después de aclarar este punto podremos seguir preguntando: ¿qué debe permanecer?, ¿qué puede y quizá debe cambiar?»»3. La respuesta a estas preguntas no puede ofrecerse desde unos presupuestos ideológicos, ni tampoco por medio de una oscilación dialéctica entre dos contrarios. Se trata más bien de ir a la misma esencia de las cosas para, desde allí, determinar cuál puede ser la mejor actualización, la mejor reforma que se puede ofrecer.

El centro de la Iglesia

La cuestión de la reforma litúrgica seguirá ocupando su interés en sus intervenciones públicas, pues como veíamos Ratzinger considera la liturgia -y su constitución conciliar- como el primer fruto del Vaticano II. En el Katholikentag de $1966^{74}$, se ocupaba también de la importancia

69 Informe sobre la fe 139.

70 «In der Spannung zwischen Regensburger Tradition und nachkonziliarer Reform», Musica sacra 114, 5 (1994) 379-389; después en JRGS 11, 549-569.

71 J. Ratzinger, Gesammelte Schriften 11, 551.

72 J. Ratzinger, Gesammelte Schriften 11, 553.

73 J. Ratzinger, Gesammelte Schriften 11, 554.

74 «Der Katholizismus nach dem Konzil - Katholische Sicht», Auf Dein Wort hin. 81. Deutscher Katholikentag, 245-266; después en El nuevo pueblo de Dios, 335356. Puede verse M. HeIm, «Konziliare Setreiflichter auf die Theologie Joseph Ratzingers / Benedikts XVI. Vortrag in Natz-Schabs (Südtirol) am 22. Oktober 2011», 55-57. 
de la Palabra en la celebración: «Fue un paso decisivo que la reforma litúrgica desritualizara la Palabra devolviéndole su función de Palabra» ${ }^{75}$. De esta forma la liturgia tiene como finalidad principal ponernos en relación directa con la palabra de Dios e introducirnos en el "nosotros» de la Iglesia. Estas finalidades son propuestas como prioritarias y fundamentales en sí mismas, hasta el punto de que legitimarían de por sí una reforma litúrgica. «Si bien la reforma litúrgica está no solo justificada, sino también se ve como necesaria, esto no quiere decir, ni mucho menos, que todas sus manifestaciones prácticas estén justificadas» ${ }^{76}$, añadía de nuevo de modo crítico. Así, por un lado se cae en arcaísmos en ocasiones idealizados, mientras en otros casos se introducen innovaciones que desentonan con el sentido del misterio que es celebrado. Así, se puede ver ahora cómo, «en un estallido de entusiasmo por el jazz», se escuchan músicas que no contribuyen al clímax celebrativo, concluía ${ }^{77}$.

La crítica continuaba. En un texto de 1985 titulado originalmente como Unidad y pluralismo del concilio al posconcilio ${ }^{78}$, tras realizar un análisis filosófico sobre el concepto de "pluralismo", el teólogo-prefecto abordaba esta cuestión en el interior de la Iglesia. "¿Domina en este ámbito -se preguntaba- el puro monismo del dogma, del magisterio, o existe también un espacio para la multiplicidad?» ${ }^{79}$. En términos concretos, ¿̨permite el Vaticano II un margen de interpretación? Para responder a esta cuestión, propone -en sintonía con los padres de la Iglesia- el concepto de «sinfonía», donde se une la unidad en la melodía con la multiplicidad de voces. Por ejemplo, en la unidad entre antiguo y nuevo testamento, entre ley y evangelio, entre profetas y apóstoles -sin caer en fáciles dialécticas-, así como la unidad entre los distintos escritos neotestamentarios. «Se trata de la forma fundamental de expresión de la verdad en la Iglesia, que tiene su fundamento en un entretejimiento rico

\footnotetext{
75 El nuevo pueblo de Dios, 341.

76 El nuevo pueblo de Dios 342.

77 El nuevo pueblo de Dios 343.

78 «Unità e pluralismo nella Chiesa dal concilio al post-concilio» en Natura e metodo della teologia. Il teologo nella disputa contemporanea. Storia e dogma (Milano 1993) 67-87.

79 Natura e metodo della teologia. Il teologo nella disputa contemporanea. Storia e dogma (Milano 1993) 75.
} 
en tensiones ${ }^{80}$. La ruptura de esta sinfonía, de esta polifonía de voces es lo que los Padres llamaron la herejía, la ruptura de esa unidad anterior. Tal unidad sinfónica ha de darse también entre Dios y cada cristiano, entre los cristianos entre sí y dentro de cada cristiano ${ }^{81}$.

De modo análogo se dará una simbiosis sinfónica entre la teología y las teologías. En efecto, mientras los dogmas, la doctrina y el magisterio corresponden a la necesidad de unidad que existe en la Iglesia y que constituyen una consecuencia de la unicidad de la verdad, las distintas teologías por el contrario corresponden a las distintas interpretaciones que se realizan de la verdad contenida en la Escritura. En este terreno se da pues un juego hermenéutico donde las interpretaciones han de encontrar esa armonía (con la verdad y entre ellas mismas), más que el simple conflicto. "Esto significa que la fe y la teología no son lo mismo, que estas tienen una voz propia, pero que la voz de la teología depende de la fe y a ella se refiere: la teología e interpretación y debe permanecer como interpretación». De igual manera que la Escritura trasciende a todas sus posibles interpretaciones, y la revelación queda como norma normans de todas las lecturas posibles. No de las reconstrucciones históricas o arqueológicas que hagan los especialistas, sino de la "sinfonía de la fe» de todos los siglos. «Solo el pluralismo -concluye-, que se refiere a la unidad, es verdaderamente grande ${ }^{82}$.

También se ocupaba de modo sucinto sobre las cuestiones expuestas en la Constitución dogmática sobre la revelación. En el libro-entrevista de 1985 donde exponía su diagnóstico sobre el posconcilio, abordaba también la exégesis y las cuestiones relacionadas con la Escritura en la vida de la Iglesia (cf. DV 22). "El vínculo entre Biblia e Iglesia se ha hecho pedazos. [...] La interpretación histórico-crítica de la Escritura ha hecho de

80 Natura e metodo della teologia. Il teologo nella disputa contemporanea. Storia e dogma (Milano 1993) 76.

81 Cf. Natura e metodo della teologia. Il teologo nella disputa contemporanea. Storia e dogma (Milano 1993) 76-77. Sobre este punto, puede verse: D. KoscH, «Schriftauslegung als Seele der Theologie. Exegese im Geist des Konzils», 205-208; P. Blanco, «Biblia, Iglesia y teología según Joseph Ratzinger», G. Aranda -J.L. Caballero (eds.), La Sagrada Escritura, palabra actual (Pamplona 2005) 389-400; versión revisada y ampliada en catalán: «La Bíblia i Jesús de Natzaret segons Joseph Ratzinger", Temes d'avui 27 (2008/1) 19-37; versión revisada en La teología de Joseph Ratzinger. Una introducción (Madrid 2011) 82-100.

82 «Unità e pluralismo nella Chiesa dal concilio al post-concilio», 77-78. 
esta última una realidad independiente de la Iglesia. Ya no se lee la Biblia a partir de la tradición de la Iglesia y con la Iglesia, sino de acuerdo con el último método que se presenta como "científico" ${ }^{83}$. El resultado final es que ambas salen perdiendo: «son vaciadas de contenido». La Iglesia se convierte en una mera organización humana, mientras «la Biblia sin la Iglesia no es la palabra eficaz de Dios» ${ }^{84}$. Esta queda a merced de la última moda filosófica o cultural. La palabra de Dios es, por el contrario -opinaba Ratzinger-, para todo el pueblo de Dios. Habría así que superar ese despotismo ilustrado, esa dictadura impuesta por los expertos que se arrogaban el derecho exclusivo de acceder a las Escrituras. "Todo católico debe tener el valor de creer que su fe (en comunión con la Iglesia) supera todo "nuevo magisterio" de los expertos, de los intelectuales»"

Años después, en 2003, con motivo de los cuarenta años de la promulgación de la Sacrosanctum concilium, el cardenal Ratzinger volvía a uno de sus temas más queridos ${ }^{86}$. Citaba allí el siguiente punto de la Constitución conciliar: «El afán por reformar y fomentar la sagrada liturgia se considera, con razón, signo de las disposiciones providenciales de Dios sobre nuestro tiempo, el paso (transitus) del Espíritu Santo por su Iglesia» (SC 43). Así, afirma de modo elocuente, «la tarea de los concilios no es producir cosas antes desconocidas, sino filtrar de entre las corrientes de una época lo que es válido, lo que realmente ha crecido a partir de la fe de la Iglesia, generando de ese modo comunidad y determinando así la dirección del camino ulterior ${ }^{87}$. Vuelve por tanto a su tesis del «desarrollo orgánico» de la liturgia. A lo que añade: «estos concilios no formulan expresiones supratemporales, cosa que, por lo demás, tampoco hace en modo alguno la sagrada Escritura, sino que condensan y dan forma de tal modo a lo que ha crecido en el tiempo que la mirada se abre más allá del tiempo y se expresan cosas de validez permanente con palabras de un tiempo determinado» ${ }^{88}$.

\footnotetext{
83 Informe sobre la fe, 82.

84 Informe sobre la fe 83.

85 Informe sobre la fe 84.

86 «40 Jahre Konstitution uber die heilige Liturgie. Rückblick und Vorblick»: J. Ratzinger, Gesammelte Schriften 11, 695-711.

87 J. Ratzinger, Gesammelte Schriften 11, 695-696.

88 J. Ratzinger, Gesammelte Schriften 11, 696; cita allí a A. Heinz, «Liturgiewissenschaftliche Forschung und liturgisches Leben der Pfarreien», en:
} 
Procuremos, pues, hacer plenamente visible en primer lugar el concepto fundamental de liturgia que desarrolla la Constitución. «En efecto -dice el texto conciliar-, la liturgia, por medio de la cual "se ejerce la obra de nuestra redención”, sobre todo en el divino sacrificio de la Eucaristía, contribuye mucho a que los fieles, en su vida, expresen y manifiesten a los demás el misterio de Cristo y la naturaleza genuina de la verdadera Iglesia» (SC 2). Nos lleva de este mundo al otro. «La liturgia nos arranca de lo visible, de lo presente, de lo cómodo, hacia la ciudad futura» ${ }^{89}$, añade nuestro teólogo. También más adelante la Sacrosanctum concilium pone de relieve el carácter cósmico de la liturgia (uno de los temas predilectos del Ratzinger teólogo), «que abarca el cielo y la tierra» (cf. SC 8). "Con la misma decisión con la que el concilio acentúa la centralidad de la liturgia para la existencia cristiana y para la esencia de la Iglesia, nos dice también, sin embargo, que la liturgia no agota la totalidad de la Iglesia (SC 9). Debe ser precedida una y otra vez por el anuncio, que conduce a la fe y a la conversión» ${ }^{90}$. La liturgia, siendo el centro y el corazón de la Iglesia, no lo es todo en ella.

En fin, abordaba el teólogo Ratzinger las «categorías fundamentales de la reforma» litúrgica: inteligibilidad, participación, sencillez. A propósito de SC 33, comentaba: «Lamentablemente, habrá que decir que, en la praxis posconciliar, el carácter instructivo se ha extendido desmesuradamente casi en todas partes, llegando incluso a imprimir un cuño escolar a la liturgia». El furor pedagogicus de algunos liturgistas ha ahogado la auténtica expresión de la misma liturgia. «Palabra y palabrería son dos cosas distintas", sentencia de modo contundente. Se refiere en primer lugar a la inteligibilidad (cf. SC 34). "Esta frase -comenta- debe entenderse sobre el trasfondo de una liturgia clericalizada, que permaneció en gran medida ajena al pueblo; y esto, no solo por la lengua latina ${ }^{91}$. Por lo que se requería un "culto razonable», como podría traducirse la expresión rationale obsequium del canon romano (cf. Rm 12,1). «La liturgia misma no puede ser transformada en una clase de religión, y no

O.H. Pesch - J. M. van Cangh (eds.), Comment faire de la théologie aujourd'hui? Continuité et renouveau, Académie Internationale des Sciences Religieuses, Session de Bose 2002 (Paris 2003) 279-289.

89 J. Ratzinger, Gesammelte Schriften 11, 698.

90 J. Ratzinger, Gesammelte Schriften 11, 700.

91 J. Ratzinger, Gesammelte Schriften 11, 705. 
puede resolverse con una banalización. Hace falta formación litúrgica o, más bien, en general, formación espiritual $»^{92}$, concluía nuestro autor. Lo esencial en la liturgia es que «su grandeza y su carácter festivo no se haga autónomo», sino que remita al único sacrificio de Cristo en la cruz y a su posterior resurrección. "La liturgia cristiana -concluye-, en la que se hace presente el amor crucificado de Dios, es la fiesta por excelencia. En esta alegre certidumbre la celebramos, y así la celebramos correctamente» ${ }^{93}$.

\section{IgLesia y MUNDO}

Pasemos ahora a las constituciones conciliares sobre la Iglesia y el mundo. Ya durante el concilio y en la citada intervención de $1965^{94}$, el joven teólogo se interrogaba de modo crítico sobre el sentido de la palabra "mundo". Realizaba así un análisis exegético y etimológico de la palabra, y concluía en la ambigüedad del término: por un lado entendido como "conjunto de actitudes contrarias a la fe» $y$, por otro, captado en un sentido positivo, derivado del "ethos cristiano ante las realidades terrenas»" Tras esto proponía una descripción del «mundo de hoy», en el que destaca a) la experiencia de la unidad del mundo y su secularidad esencial y b) la constatación de la «maleabilidad del mundo». Con el descubrimiento de América (y el conocimiento más profundo de otros continentes, podríamos añadir), «el mundo se ha convertido en un "mundo" que es uno e idéntico». Se ha dado una desmitologización de la imagen del mundo, ampliando sus límites visibles, lo cual supone un verdadero reto para la fe. «Si la fe no quiere disolverse en lo anacrónico, debe tomar los nuevos

92 J. Ratzinger, Gesammelte Schriften 11, 707.

93 J. Ratzinger, Gesammelte Schriften 11, 711.

94 «Angesichts der Welt von heute. Überlegungen zur Konfrontation mit der Kirche im Schema XIII», Wort und Wahrheit 20 (1965) 493-504; versión ampliada: "Der Christ und die Welt von heute. Überlegungen zum sogenannten Schema XIII des Zweiten Vatikanischen Konzils» en B. MEtz (ed.), Weltverständnis im Glauben (Mainz 1965) 143-160; versión revisada: «Der Christ und die Welt von heute», Dogma und Verkündigung, 183-204; tr. esp.: Palabra en la Iglesia, 147-164. Puede verse también «Das Menschenbild des Konzils in seiner Bedeutung für die Bildung», Kulturbeirat beim Zentralkomitee der deutschen Katholiken (ed.), Christliche Erziehung nach dem Konzil. Berichte und Dokumentationen 4 (Köln, 1967) 33-65.

95 Cf. Palabra en la Iglesia, 154-155. 
datos como condiciones previas a sus afirmaciones; y en esta tarea le queda mucho por hacer ${ }^{96}$. "Lo más importante-concluía- es el intento de despertar las conciencias y llamarles la atención sobre la responsabilidad ante Dios que se ha manifestado en Jesucristo como palabra y como amor $»^{97}$.

"¿"Mundocentrismo"?»

Dios no puede disolverse en el mundo que él mismo ha creado. En la citada intervención en el Katholikentag de $1966^{98}$, el antiguo perito conciliar proponía la relación del cristiano con el mundo como el principal campo de prueba para entender el modo en que viene siendo aplicado el concilio. La imagen de la catedral neoyorquina dedicada a san Patricio, rodeada de rascacielos, podría ser emblemática para entender cómo se encuentra la Iglesia en medio del mundo moderno. Tal vez se encontraba un poco perdida. Pero no es esta relación una mera cuestión de contraste de estilos (la catedral neogótica junto a los rascacielos ultramodernos), sino que había que ir más en profundidad. Por eso Ratzinger proponía dos visiones complementarias. La primera sería la incarnacionista: Dios se ha hecho carne, y por eso resulta un Dios especialmente cercano, «un Dios cabalmente de este mundo»99. La otra postura sería la "escatológica», más en la línea de la teología de la cruz. Ambas corrientes confluyeron en la redacción de la Constitución pastoral sobre la acción de la Iglesia en el mundo. Sin embargo, el posconcilio se quedó tan solo con el optimismo incarnacionista, ajeno al pecado y a la cruz, sentenciaba Ratzinger. Lo curioso era que el escándalo cristiano de la cruz no ha querido nunca ser suprimido por el concilio.

Según Weimann, la de Ratzinger sería más bien de una orientación cristocéntrica y eclesiológica, y no solamente antropocéntrica o "mundocéntrica" más propia de la teología de la secularización ${ }^{100}$. También

\footnotetext{
96 Palabra en la Iglesia 157.

97 Palabra en la Iglesia 164.

98 "Der Katholizismus nach dem Konzil - Katholische Sicht», Auf Dein Wort hin. 81. Deutscher Katholikentag, 245-266; en El nuevo pueblo de Dios, 335-356. Puede verse también "Offene und verschlossene Kirche», JRGS 8/2, 1214-1215.

99 Cf. El nuevo pueblo de Dios, 348-349.

100 Cf. R. Weimann, «Hermeneutik der Reform als Erneuerung in Kontinuität», 77.
} 
en un texto aparecido en $1973^{101}$, comenzaba por analizar la crisis del primer posconcilio y de la orientación que han tenido la enseñanzas conciliares en clave de Gaudium et spes. Junto a un progresismo generalizado -sostenía - se había dado un cambio generacional de la primera a la segunda generación de la posguerra. El mundo que esta se encontraba ya estaba reconstruido, y no quedaba nada por hacer; a su vez, no ofrecía ningún sentido pues había sido disuelto en la subjetividad del existencialismo. Para colmar este vacío, surgieron el neopositivismo y el neomarxismo. Según el diagnóstico que establecía Ratzinger, había dos aspectos que caracterizan estas corrientes: «el adiós a la historia y el adiós a la metafísica». La historia era considerada un lastre y un obstáculo para el progreso. «Solo desde este presupuesto se explica la rapidez con que han caído en el olvido las verdaderas intenciones y afirmaciones del Vaticano II, para ser disueltas primero con la utopía del Vaticano III, y luego por los sínodos, que hacen valer en todo caso el "espíritu", pero nunca los textos del Vaticano II» ${ }^{102}$. El «adiós al ser» consistiría en convertir la realidad presente en mera escatología, donde esta se convierte en utopía y en una supuesta esperanza expresada en términos ideológicos. "El hombre mismo es el creador escatológico, al que no precede logos alguno, sino que al que le seguirá: en el principio no se encuentra la "palabra", sino la "acción"»"

En un artículo de 1975 sobre la aplicación y el influjo de la Gaudium et spes ${ }^{104}$, el teólogo Ratzinger expresaba su perplejidad por la evolución de las esperanzas a partir de la pentecostés conciliar. ¿Dónde estaba el gaudium et spes, la alegría y la esperanza?, se preguntaba. Sin embargo, después, con perspectiva histórica (aparecen allí por ejemplo Eusebio de Cesarea, Gregorio de Nisa, Basilio el Grande, Lutero), abordaba la situación actual, para encuadrarla dentro de un marco de normalidad inme-

101 «El posconcilio y la Iglesia» en Palabra en la Iglesia, 318-324.

102 Palabra en la Iglesia 320.

103 Palabra en la Iglesia 321. Cf. S. MAdrigal, Karl Rahner y Joseph Ratzinger, 142-145.

104 «Der Weltdienst der Kirche. Auswirkungen von Gaudium et spes im letzten Jahrzehnt», Communio 4 (1975) 439-454; en A. BAUCH - A. Glässer - M. SeYbold (Hg.), Zehn Jahre Vaticanum II (Regensburg 1976) 36-53; también como "Kirche und WeIt: Zur Frage nach der Rezeption des II. Vatikanischen Konzils» en Theologische Prinzipienlehre, 395-411; tr.it.: "A dieci anni dal Vaticano II», Rivista del clero italiano 57 (1976) 2-4. Cf. S. MADRIGAL, Karl Rahner y Joseph Ratzinger, 145-150. 
diatamente posconciliar. "Al concilio de Nicea, afirmaba con realismo, que fijó la fórmula definitiva de la filiación divina de Jesús, le siguió una época de desmoralizadoras discusiones, que desembocaron en el primer cisma de la Iglesia, el arrianismo, y desgarró durante decenios a la Iglesia hasta los niveles más profundos» ${ }^{105}$. Así pues, la evolución crítica del primer posconcilio se inserta en una larga historia. No iba a ocurrir de un modo diverso en este concilio respecto a los anteriores... Junto a los evidentes logros positivos, se sigue una serie de consecuencias negativas. Sin embargo, "quien se atreve a denunciar tales cosas es inmediatamente tachado de pesimista y excluido del diálogo. Pero aquí se trata pura y simplemente de hechos empíricos, y creerse en el deber de negarlos no es optimismo, sino tácita desesperación. No: ver los hechos como son no es pesimismo, sino realismo» ${ }^{106}$, concluía.

Frente a esta situación proponía, en primer lugar, conocer los límites de los propios concilios y, después, abordar la cuestión de «la correcta aceptación del Vaticano II». Así, describía primero la función terapéutica de los concilios en la vida de la Iglesia: "son medicina, no alimento», y toda medicina requiere de un tiempo de asimilación. Además, el concilio no lo es todo, pues esto supondría incurrir en un exceso conciliarista. «Dicho sin imágenes: el concilio es un órgano de consulta y decisión. En cuanto tal, no es un fin en sí mismo, sino que tan solo tiene un valor instrumental» ${ }^{107}$. No se trata de discutirlo todo. Lo esencial en el cristianismo es la Palabra, los sacramentos y el amor al prójimo. Por eso, se requería una correcta asimilación de la doctrina conciliar. La palabra-clave del concilio -a su modo de ver- era communio, lo cual no significa multiplicar reuniones o documentos, sino fomentar esa comunión con Dios y entre nosotros. Así, por ejemplo, la colegialidad sería complementaria al ejercicio de la dimensión personal del ministerio episcopal. En fin, continuando una imagen de Karl Rahner, concluía: «El factor decisivo es si hay o no personas -santos- que, mediante el compromiso inamovible de su propia persona, acierten a crear cosas nuevas y vivas» ${ }^{108}$.

Recordaba pues Ratzinger un principio hermenéutico: no se puede establecer esta constitución conciliar como el único texto, ni siquiera

105 Teoría de los principios teológicos, 442.

106 Teoría de los principios ..., 443.

107 Teoría de los principios ..., 448.

108 Teoría de los principios ..., 453. 
como la mejor expresión de un presunto «espíritu del concilio» que contendría toda la esencia de la verdad. "No es la Constitución pastoral la norma y la medida de la Constitución sobre la Iglesia, y menos aún la intención -sacada de contexto- de los párrafos de la introducción, sino al revés: solo la totalidad, en su exacta centralización, es el auténtico espíritu del concilio» ${ }^{109}$. Lo que ha hecho daño a la Iglesia no era el concilio, sino un determinado sucedáneo: «La tarea no es pues ignorar el concilio, sino descubrir el concilio real y profundizar en su auténtica voluntad, a la luz de las experiencias vividas hasta entonces ${ }^{110}$. Tras aludir a los excesos quijotescos de quema de libros y renuncia a toda realidad anterior, terminaba Ratzinger afirmando que «hemos tapiado, orgullosos y seguros de la victoria, la puerta de una época del pasado y declarado ya disuelto y desaparecido todo que había detrás de ella» ${ }^{11}$. No podemos convertirnos en unos nostálgicos, en unos románticos del pasado -concluye-, pero «debemos estar preparados para aceptar con una nueva mentalidad lo que, en las vicisitudes de los tiempos, es auténtico soporte» ${ }^{112}$. Es decir, aquello que es esencial y sirve como fundamento perenne y estable.

Había que leer el concilio en su conjunto y como una unidad. Pero sobre todo había que leer el concilio, y uno solo determinadas interpretaciones, a veces contrarias a la misma letra del Vaticano II. En el Informe sobre la fe, que es también un informe sobre el primer posconcilio, el cardenal bávaro enunciaba de modo claro esta difícil y controvertida relación: «El Vaticano II tenía razón al propiciar una revisión de las relaciones entre Iglesia y mundo. Existen valores que, aunque hayan surgido fuera de la Iglesia, pueden encontrar -debidamente purificados y corregidos- un lugar en su visión. [...] Pero demostraría no conocer ni a la Iglesia ni al mundo quien pensase que estas dos realidades pueden encontrarse sin conflicto y llegar a mezclarse sin más» ${ }^{113}$. De nuevo volvía al concepto de mundo que se contiene en los documentos conciliares. Se trataría pues de ser conscientes -concluía allí- de que el mundo se opone de modo decidido a la gracia. Tras evitar una «eufórica solidaridad

\footnotetext{
109 Teoría de los principios ..., 469.

110 Teoría de los principios...

111 Teoría de los principios ..., 472.

112 Teoría de los principios...

113 Informe sobre la fe, 42.
} 
posconciliar» con el mundo, debemos encontrar de nuevo «el coraje del anticonformismo, la capacidad de oponerse, de denunciar muchas de las tendencias de la cultura actual» ${ }^{114}$.

\section{La Esposa de Cristo}

«El concilio Vaticano II ha sido un concilio "eclesiológico", en el sentido de que la dirección a la que se han dirigido los padres [conciliares] ha sido la profundización en el misterio de la Iglesia y en su profundización» ${ }^{115}$. Esta afirmación constituye una premisa para nuestro autor. En la citada intervención en el Katholikentag de $1966^{116}$, Ratzinger hablaba entonces de un "giro hacia el ecumenismo» en el primer posconcilio. En primer lugar, como era de esperar, el teólogo se congratulaba por los avances ecuménicos que habían tenido lugar en torno al concilio. Aunque al mismo tiempo advertía en ese primer posconcilio un cierto sentimiento «triunfalista» que olvidaba dar gracias al Padre por Cristo en el Espíritu. Además, constataba un cierto acriticismo, porque «no se mide ni se interroga críticamente el propio criterio». A esto se unía la «ingenua prisa» de dar por terminadas las disputas teológicas que han ocupado durante siglos a las distintas confesiones cristianas. Así, por ejemplo, se utiliza de un modo indistinto el término "Iglesia", sin atenerse a la realidad eclesial designada. Como reacción había surgido en la Iglesia un integrismo que consideraba el ecumenismo como algo acatólico. Por lo que hacía un llamamiento a la paciencia, «la forma ordinaria de la caridad» y que está íntimamente unida a la esperanza ${ }^{117}$. Junto a esto llama a la humildad, que evita toda vanagloria en torno al concilio. «Mientras el mundo sea mundo -concluye-, la Iglesia se encuentra en peregrinación al encuentro del Señor. El concilio no es un albergue en el que pueda acomodarse uno y olvidarse del camino: es un andar hacia delante al encuentro del Señor ${ }^{118}$.

\footnotetext{
114 Informe sobre la fe, 43.

115 «Presentazione» a L. SChefFCzyк, La Chiesa: aspetti della crisi conciliare e corretta interpretazione del concilio Vaticano II (Milano 1998) 9.

116 «Der Katholizismus nach dem Konzil - Katholische Sicht», Auf Dein Wort hin. 81. Deutscher Katholikentag, 245-266; en El nuevo pueblo de Dios, 335-356.

117 Cf. El nuevo pueblo de Dios 354-355.

${ }_{118}$ El nuevo pueblo de Dios 356.
} 
Junto con la liturgia, Ratzinger consideraba como una clave interpretativa de todo el concilio la Constitución dogmática sobre la Iglesia en su relación con el mundo ${ }^{119}$. En una intervención de 1966 en un centro ecuménico protestante ${ }^{120}$, nuestro autor abordaba las cuestiones que había planteado el encuentro de las teologías luterana y católica en el posconcilio. Hablaba allí de dos grandes pilares del concilio constituidos por las constituciones sobre la Iglesia y el mundo. Al mismo tiempo, relacionaba también la Lumen gentium con la Dei verbum, para destacar la relación entre la Palabra y la Iglesia, si bien las concepciones católica y protestante difieren en este punto. También se refiere al término «Iglesias", en plural, aplicado no solo a las Iglesias orientales sino también a lo que el concilio llama "Comunidades eclesiales» surgidas a partir de la Reforma. En este sentido, consideraba latente en estos desarrollos la concepción conciliar la doctrina del subsistit in, expuesta en LG 8. Solo hay una Iglesia de Cristo, con la que puede haber una mayor o menor comunión: "Desde la interpretación católica de la Iglesia, el plural "Iglesias" solo puede darse a las Iglesias locales dentro de la unidad de la única Iglesia»" ${ }^{121}$.

Por el lado católico, cabía el peligro de identificar la Iglesia con el reino de Dios, por lo que aquella no necesitaría reforma ni perfeccionamiento alguno. Cabría también por el contrario la posibilidad de ver en la Iglesia solo pecado y apostasía. Por un lado, se adelantaría el eskathon; por otro, se retrasaría, convirtiendo a la Iglesia en un eterno peregrinar. En ciertas concepciones del concepto de pueblo de Dios estaban presentes estas ideas. Por eso Ratzinger proponía superar una idea «acristológica» de la noción de pueblo de Dios. Si anteriormente se había teni-

119 Cf. S. Madrigal, Karl Rahner y Joseph Ratzinger, I67-I68; M. HeIM, «Konziliare Setreiflichter auf die Theologie Joseph Ratzingers / Benedikts XVI. Vortrag in Natz-Schabs (Südtirol) am 22. Oktober 2011», 54-55.

120 Conferencia pronunciada en el Instituto ecuménico de la Confederación luterana mundial el 24 de febrero de 1966, en el Liebfrauenberg de Alsacia, recogida como "Theologische Aufgaben und Fragen bei der Begegnung lutherischer und katholischer Theologie nach dem Konzil» en F. W. Kantzenbach - V. Vatja (Hg.), Oecumenica 1969 (Gütersloh 1970) 251-270; también en Das neue Volk Gottes, 225-245. Puede verse también «Presentazione» a L. Scheffczyk, La Chiesa: aspetti della crisi conciliare e corretta interpretazione del concilio Vaticano II, 9-11.

121 El nuevo pueblo de Dios, 255; sobre este punto, puede verse S. Lefebvre, «El conflicto de las interpretaciones del concilio: el debate entre Ratzinger y Kasper", 111-116. 
do una concepción puramente juridicista de la pertenencia a la Iglesia, ahora cabría el error contrario de caer en un mero espiritualismo. Por el contrario, Ratzinger opinaba que se trata de unir lo exterior y lo interior, la pertenencia a la Iglesia con la acción de la gracia. Así, LG 14 habla de la posesión del Espíritu de Jesucristo. "Con esto se había puesto en juego, de manera conmovedora, la cuestión de la Iglesia de los santos, de la santidad como exigencia esencial de la Iglesia» ${ }^{122}$. Esto exige por nuestra parte no solo penitencia y purificación, sino también amor, pureza y «aceptación del otro». En este sentido, habría que entender el cuerpo de Cristo como "cuerpo resucitado». Por tanto, cristología y pneumatología se unirían en el concepto de Iglesia, como lo exterior y lo interior en ella. «Muchas antítesis caen por su propio peso y la cuestión se sitúa en un nuevo plano de posibilidades» ${ }^{123}$.

En el mencionado texto de 1985 titulado originalmente como Unidad y pluralismo del concilio al posconcilio ${ }^{124}$, explicaba cómo la unidad sinfónica se había de dar entre la Iglesia universal y las distintas Iglesias locales, entre primado y episcopado, entre el ministerio de unidad de Pedro y la colegialidad entre los numerosos hermanos en el episcopado. "De la coordinación correcta entre todos estos factores depende la "sinfonía" de la Iglesia en las muchas Iglesias»" ${ }^{125}$, afirmaba en la línea de la eclesiología eucarística de comunión. En esta mutua implicación, se combinan los elementos personal y comunitario, sin caer ni en monocracias ni en falsas democracias. «La Iglesia como comunidad -añadía más adelante-, que se basa en la conciencia, puede permitirse introducir la conciencia como un elemento fundamental en su constitución y así unir entre sí comunidad y personas. [...] Precisamente esta forma personalista de [ejercer] el derecho y la personalidad promueve un variado y vital pluralismo: el colegio episcopal es un cuerpo que se compone

122 El nuevo pueblo de Dios 270.

123 El nuevo pueblo de Dios 273; cf. S. Lefebvre, «El conflicto de las interpretaciones del concilio: el debate entre Ratzinger y Kasper», 117-118.

124 «Unità e pluralismo nella Chiesa dal concilio al post-concilio», Bollettino diocesano per gli ufficiali e attività pastorali dell'arcidiocesi di Bari 61 (1985) n. 1; en Orientamenti pastorali 12 (1985) 125-144; tr. al.: "Pluralismus als Frage an Kirche und Theologie», Forum Katholische Theologie 2 (1986) 81-96; tr. fr.: «Le pluralisme: problème posé à l'Église et à la théologie», Studia Moralia 24 (1986) 299-318; después en Natura e metodo della teologia, 67-87.

125 Natura e metodo della teologia 78. 
de aquellos que detentan una específica responsabilidad última hacia la Iglesia particular, la cual es la misma Iglesia en su integridad y en ella los obispos cumplen su propia responsabilidad respecto a la Iglesia universal. Solo de esta forma el colegio episcopal es un grupo plenamente vital, que refleja la multiplicidad el Espíritu en la única Iglesia» ${ }^{126}$.

En la entrevista realizada a los veinte años del final del concilio, Ratzinger volvía a afirmar que la raíz de la crisis posconciliar era «la idea de Iglesia». «Mi impresión -diagnosticaba- es que se está perdiendo de modo imperceptible el sentido auténticamente católico de la realidad "Iglesia", sin rechazarlo de manera expresa»" ${ }^{127}$. Al quedar en sordina la dimensión universal, la Iglesia se estaría empequeñeciendo y disolviéndose en pequeños particularismos, podríamos decir tal vez en términos un tanto alarmistas. La Iglesia se presentaba también en algunos planteamientos como separada de su origen y de la misma voluntad de Cristo. "Algunas eclesiologías posconciliares parecen inspirarse directamente en el modelo de ciertas "Iglesias libres" de Norteamérica". Aquellos prófugos -continúa-, "no creyendo ya en la Iglesia querida por Cristo», "crearon su propia Iglesia, una organización estructurada según sus necesidades» ${ }^{128}$. La alergia a la unidad institucional sería una característica común que las uniría a todas ellas. Por eso insiste una y otra vez en el carácter sobrenatural de la Iglesia: «Detrás de la fachada humana está el misterio de una realidad suprahumana, sobre la que no pueden intervenir en absoluto ni el reformador, ni el sociólogo, ni el organizador». De este modo se requiere una "visión sobrenatural» y no meramente sociológica del misterio de la Iglesia. En el fondo de esta cuestión, concluía, se encuentra un problema de carácter cristológico, donde la naturaleza divina de Jesucristo queda en un segundo plano. La Iglesia queda reducida al «proyecto Jesús», al «proyecto liberación social» o a «otros proyectos meramente históricos» ${ }^{129}$.

En la intervención que tuvo el 26 de noviembre de 1985, durante la celebración del Sínodo extraordinario celebrado a los veinte años del Vaticano II, el cardenal prefecto apelaba a la tam amplam et profundam

126 Natura e metodo della teologia 79; cf. S. LEFEBVRE, «El conflicto de las interpretaciones del concilio: el debate entre Ratzinger y Kasper», 120-122.

127 Informe sobre la fe, 53.

128 Informe sobre la fe 54.

129 Informe sobre la fe 
doctrinam de Ecclesia propuesta por el concilio. En estos veinte años hemos de constatar un cambio hacia "la sospecha y la desconfianza", mientras le parecía experimentar un descenso del amor y del sentido de la Iglesia. "Esto supone una auténtica carencia para la eclesiología actual, que solo habla de la distribución de la potestad, olvidándose de lo que supone la Iglesia como tal: dimensionem mysterii Sponsae, de quo Concilium tam pulchre locutus est». La Iglesia es sobre todo el misterio de la Esposa de Cristo. Por eso Ratzinger apelaba a una «eclesiología integral", tal como hizo el concilio al fundamentarla en la Escritura y los Padres, que siempre se ha de dirigir a toda la humanidad ${ }^{130}$. En definitiva, la clave consistiría en volver a la concepción teológica de la Iglesia, como misterio de comunión de la Trinidad con la humanidad y de los cristianos entre sí, como pueblo de Dios y cuerpo de Cristo, como su Esposa y como sacramento universal de salvación.

La cuestión de la hermenéutica conciliar ha vuelto a salir de un modo sintético y equilibrado durante su magisterio como obispo de Roma. Ofreció así una clave de lectura cuando Benedicto XVI dirigió su alocución a la Curia romana en 2005 para afirmar una "'hermenéutica de la reforma”, de la renovación en la continuidad del único sujeto-Iglesia, que el Señor nos ha dado; es un sujeto que crece en el tiempo y se desarrolla, permaneciendo siempre, no obstante, el mismo y único sujeto del pueblo de Dios en camino» ${ }^{131}$. No se trata ni de una mera continuidad, ni tampoco de una pura ruptura revolucionaria, sino de una reforma, de «la renovación en la continuidad»: «a la hermenéutica de la discontinuidad se opone la hermenéutica de la reforma» ${ }^{132}$, que implica continuidad en los principios, pero discontinuidad en las formas históricas de comprenderlos y de llevarlos a la práctica. Un concepto sutil y un equi-

1304 4o Congregazione (26.11.1985), W. Kasper, Risposta alla Segretaria del Sinodo (Città del Vaticano, Segretaria generale del Sinodo 187/85) 154; texto en F.S. Venuto, La recezione del concilio Vaticano II nel dibattito storiografico dal 1965 al 1985 (Torino 2011) 391.

131 Benedicto XVI, Allocutio ad Romanam Curiam ob omina natalicia, AAS 98 (2006) 1, 46. En esta línea, puede verse: M. L. LAMB - M. Levering, «Introduction», 7; R. Weimann, "Hermeneutik der Reform als Erneuerung in Kontinuität», 59-61, 78-82; J. Комоnснак, "Benedict XVI and Vatican II», 325-326. En las páginas siguientes, el historiador estaunidense se muestra crítico con la postura expuesta por el Papa en el discurso de 2005 (cf. ibid., 327-337).

132 Benedicto XVI, Allocutio ad Romanam Curiam ob omina natalicia, 47. 
286 | Pablo Blanco Sarto

librio difícil de alcanzar. No vale un esquema maniqueo, dialéctico o ideológico para entender el concilio, sino en algo más equilibrado y matizado. No es ni una creatio ex nibilo ni una revolución, sino la reforma entendida en sentido clásico: como reformatio, como purificatio, como mutatio in melius ${ }^{133}$. "Precisamente en esta conjunción de continuidad y discontinuidad en niveles diferentes consiste la verdadera naturaleza de la reforma» ${ }^{134}$, concluía Benedicto XVI.

133 Cf. J.W. O’MALLEY, “"The hermeneutic of reform”: a historical analysis», 542-546.

134 Benedicto XVI, Allocutio ad Romanam Curiam ob omina natalicia, 49. 
Resumen: En las siguientes líneas se ofrece una síntesis de las ideas de Joseph Ratzinger sobre el concilio, en la que aparece una continuidad y una maduración de las ideas teológicas formuladas durante el concilio, y que hemos estudiado con anterioridad. En primer lugar, estudiamos dos conceptos-clave que servirán de punto de partida para la hermenéutica conciliar: los de «reforma» y aggiornamento. Después se abordan cuestiones más concretas como son las valoraciones que realiza el teólogo Ratzinger sobre la reforma litúrgica auspiciada por el Vaticano II, así como la importancia complementaria de la Palabra en la Iglesia. En fin, recorremos la idea que formula el teólogo alemán sobre las constituciones Gaudium et spes y Lumen gentium, en las que ve una perfecta línea de continuidad en sus presupuestos eclesiológicos.

Palabras clave: Aggiornamento, liturgia, Iglesia, mundo, reforma.

Abstract: This paper contains Joseph Ratzinger's ideas on the question of continuity or break of Vatican II with the preceding tradition. The study starts with two keywords "reform" and aggiornamento. Then follows Ratizinger's judgment on the application of the liturgical reform and the reading of the Bible in the Church. And finishes with his thought on the continuity of Gaudium et Spes and Lumen Gentium.

Keywords : Aggiornamento, liturgy, Church, world, reform 
